\title{
LTAD Model Active Beginning Stage Adaptation in Judo Basic Education Program (Ukemi, Tachiwaza \& Newaza Basic Drills) for 4-6 Aged Kids
}

\author{
Sengul Demiral \\ Correspondence: Sengul Demiral, Kirkpınar College of Physical Education and Sports, Edirne Trakya University, \\ Turkey.
}

Received: October 15, 2018

doi:10.11114/jets.v6i12a.3715
Accepted: October 23, $2018 \quad$ Online Published: October 24, 2018

URL: https://doi.org/10.11114/jets.v6i12a.3715

\begin{abstract}
Early childhood is known as a critical period in acquisition of development and basic mobility skills. In this period, physical education and judo education contribute to development of general body, hand-eye and foot-eye coordination, 5 motor skills, static and dynamic balance. Moreover, the sub-structure of lifelong sport habits is being prepared by teaching values with respect to judo, kindness, self-determination, solidarity, honesty, friendship, patience, courage and modesty. As a result, due to basic education of judo such as 'Ukemi, Tachi Waza and Newaza Basic Drills', children learn much more than movement skills. In this study, importance of physical education and judo activities in pre-school period has been considered in practice. The results showed Judo has an impact on pre-service and in-service training in practice of pre-school physical education and judo activities. It is inevitable that these activities contribute to almost all targeted development areas of a child, in addition to contributing to training of large group of children in first phase of long-term athlete development model in our country.
\end{abstract}

Keywords: Pre-School Period, Judo, Activist Starter, Ukemi, Tachiwaza \&Newaza

\section{Introduction}

Judo, which is one of the most popular sports in the world and is an attractive in almost every country since judo athletes and spectators enjoy watching exciting movements. Judo deals with high intensity, intermittent physical activities and well developed for aerobic and anaerobic performance. Judo needs a high degree of technical skills, strength, coordination, static and dynamic balance, agility and durability. In terms of health promotion, judo is a very suitable for promotion of lifelong activity and health because it has training systems covering all age groups. For this purpose, there are projects carried out worldwide. One of these projects is Ukemi School children project, the other one is carried out by EJU (European Judo Association) to prevent trauma and injuries caused by the fall of children. According to European Judo Association, it is not only a sport but a system of education too. The founder of Judo Sport Jigoro Kano himself introduced it not only for physical training but also as a moral and social discipline. Jigoro has believed that one of the best ways to promote sport is to promote judo at schools. Since the course could be adapted in school environment. In addition, "ukemi/fall" exercises may be conducted with special judo training methods. To learn Ukemi (fall), everybody gets flexibility, slows down speed of falling with hands and feet, protects head, reduces number of injuries caused by falling accidents or at least reduces accidents in an ideal way; Ukemi methods can be taught solely, in pairs or in a groups with fun movements. All these strategies and action plans are a great way to bring judo to school environment. It is also a great way for children, teachers and parents to discover Judo (http://www.eju.net/judo-ukemi-lessons-at-school. Access: 20/08/2018).

All these are positive manners not only for the development of our sport, but also for the first stage of the long-term athletic development model (LTAD). At this point, we can see the contribution of judo sport to the group of 4-6 aged children's development in many literature studies. In judo education, children are mentally strong; they learn the art of struggle based on practical intelligence, rapid retention, reasoning power, quick decision-making ability, and physically reflecting the whole-body power to the balanced and targeted point (Demiral, 2007).

When we try to explain sport more broadly as educational science, judo is a sport that requires a high level of skills. The development of analytic functions, ability to identify quickly, act in ever-changing conditions of competition are certain features that are expected to occur in this sport. In addition, decisions of athletes in case of a complex game depend on their ability to perceive external stimuli. The levels of quick thinking and interpretation are factors which help opponent 
to achieve a successful tactical behavior or help his/her team succeed (Bompa, 2007; Brosse, Matsumoto, 1999).

In many countries around the world, judo trainings have been started to be given in preschool because training of judo covering a period of 10,000 hours or 10 years, or a long period of 100.000 Uchikomi (working method in series application of judo special technique). Because of philosophical structure of judo education (Ju: Softness, flexibility, Do: Road; the path followed to reach a goal, all of methods) can be seen as a separate factor in contribution of children to education of values. When we review literature studies, it has been seen that a skilled athlete should be trained for at least 10 years or 10.000 hours in order to reach sporty perfection, and this process is called as ' 10 years rule' (Balyi ve ark., 2003). It is the point which this study has criticized it. In this system, development process of athletes is planned according to the age (Açıkada, 2016). Although this model has been criticized, successes of countries such as Canada and the United Kingdom in international sport organizations are clearly seen. When a more detailed literature review was conducted, LTAD was determined as a desired model for athletes' development in Canada by comparing development programs of countries such as England and Ireland. The LTAD has developed this model to respond to a need for development of elite athletes for international competition and also to encourage Judo as an active lifestyle for all ages. The long-term sport development model developed by Canadian sports centers (LTAD) is used in many countries and is being implemented successfully. Today, one of main reasons for beginning of education is to think that Olympic education programs should be started from primary periods. It is thought that OEP (Olympic Education Program) can be started in primary schools and it can make system more successful in all education stages. Long-term Olympic education program effectively and efficiently for the implementation of all relevant authorities NOC (National Olympic Committee of Turkey) and chaired by IOC (International Olympic Committee) should work in coordination with support. This program is supported with LTAD model and it is thought that success might be more sustainable (Özbey and Güzel, 2009). At this point, planning, conducting, receiving feedback and career planning of long-term sports development model are emerging. From this viewpoint, adaptation of activity period of 'long-term athletic development model', which consists of 7 stages, as first stage of judo training might be examined. This study covers adaptation of the first stage of LTAD development model in judo. Therefore, this study is thought to be an exemplary model for use in preschool education especially in our country and only training of judo for the first phase of 4-6 age groups (girls and boys) would be examined. When the model is integrated in judo and when is gazed at program in development of LTAD judoists, we see that model consists of seven stages:

Stage 1: Active Start (0-6 boys and girls),

Stage 2: Fundamentals (6-8 girls - 6-9 boys),

Stage 3: Learn to Train (8-11 girls - 9-12 boys),

Stage 4: Train to learn (11-15 girls - 12-16 boys),

Stage 5: Train to Compete (15-19 girls - 16-20 boys),

Stage 6: Train to Win $(18+$ girls - 19+ men $)$,

Stage 7: Active for Life

1.1 Active Start Stage for Judo Sports; 4-6 Age Period for Ukemi,

\section{Tachiwaza, Newaza Basic Directive Training Course}

The aim is to enable children to move, be active and provide opportunities for children to learn basic knowledge of judo in schools, clubs, recreation centers and homes. The aim is not based on competition and should be accompanied with educational games with high content that enables adults and children to act together. Judo training methods should include Ukemi, Tachiwaza, Newaza and basic resistance 'training systems. Physical education programs should be developed in order to teach basic movement skills (such as running, jumping, turning, throwing, grasping, etc.). It is particularly good to apply this to start and end sections of a training zone. The basic part of training should include training Ukemi, Tachiwaza and Newaza Foundation Resistors Coaching. A mixed education model and well-structured physical education programs are proposed to raise physical development and broad-based basic mobility skills (Özkan and Özkan, 2016). At this point, these training methods should be constructed with mentioned points.

\section{Materials and Methods}

A compilation study was conducted in this study. The data were obtained from local and foreign references and documents. Domestic and foreign articles, books, journals, reports, various articles and documents obtained through internet were collected and arranged in line with stated purpose and adapted to training method of judo. Growth and development have effect of gaining basic movement skills in children. In addition, opportunities for children and movement training play an important role in a balanced development of basic movement skills. Judo supports cognitive skills such as development of thinking and problem-solving skills, concept development. Small and large muscle motor 
development supports development of emotional and social life skills. With help of Judo, bodily awareness of child is increased and infrastructure of lifelong sports habit is prepared. As a result, by Judo training due to Ukemi, Tachiwaza and Newaza Basic Resistance, children get much more than their mobility skills (Demir, 2007; Kano, 2005). In this study, importance of judo education and educational game activities of judo (Ukemi, Tachiwaza and Newaza Temel) in preschool period have been taken into consideration and sample education program tables have been given. In long-term sports development model, table below shows where and by whom basic movement skills have been given.

Table 1 . The table where the basic movement skills are shown and by whom.

\begin{tabular}{l|l|l}
\hline Location & Physical Education & Who Can Do \\
\hline $\begin{array}{l}\text { schools, sports clubs, communities, recreational } \\
\text { sports programs, }\end{array}$ & $\begin{array}{l}\text { basic stage boys and girls (4-6 } \\
\text { years) }\end{array}$ & $\begin{array}{l}\text { teachers, creative leaders, young leaders, } \\
\text { young, coaches }\end{array}$ \\
\hline $\begin{array}{l}\text { Preschool, kindergarten, } \\
\text { sports programs, communities, recreational areas }\end{array}$ & $\begin{array}{l}\text { Active start, basic movement } \\
\text { training; Girls and boys (0-6 year) }\end{array}$ & Kindergarten teachers \\
\hline
\end{tabular}

The most important point to be considered here is that judo trainers and kindergarten teachers work very effectively in execution of program. Training should be provided entirely by judo trainers. It is also effective in creating employment for many people working in this field. In long-term sports development program, planning and implementation of judo training program of children (4-6 years old) might be dealt with appropriate planning of studies. At this stage, we can examine key concepts as follows.

$>\quad$ Judo training program; Ukemi, Tachiwaza and Newaz Basic Education and physical activity are a part fun of a child's life every day and necessity for healthy child development,

$>\quad$ Active games are important at this stage because they make important connections between brain and muscles of children.

$>$ Opportunities for risk and limit research in safe environments should be given,

$>$ Provide unstructured access to a wide range of colorful toys and equipment and allow a child to be structured,

$>\quad$ Activities should help to make children feel competent and comfortable in a variety of fun and challenging activities and non-competitive games,

Table 2. Examples of active beginning and basic movement skills in physical education

\begin{tabular}{l|l}
\hline Locomotor Skill & $\begin{array}{l}\text { Climbing (rope), Splash (boy-calp) } \\
\text { Running (joggıng), Creep (newaza creep), Jump (skipping rope) }\end{array}$ \\
\hline $\begin{array}{l}\text { Manipulative Movements (Object Control } \\
\text { Skills) }\end{array}$ & $\begin{array}{l}\text { Kuzushi with Tire, Kake (lifeless mannequin) with Belt, Capture (Kumikata / Grip) } \\
\text { dribbling }\end{array}$ \\
\hline Balance Movements & Balance, Body with rolling (newaza basic drills, uchi mata, harai goshi) \\
\hline
\end{tabular}

Basic movement skills and basic judo skills can be provided in development of skills with fun movements and short educational games. In development of basic skills, it is very important to provide many opportunities for children to explore their movement potential through educational games (Demiral, 2010). In active initiation period, games that encourage judo educational games, not only run in a straight line but in different directions, including, chasing, dangling, head and direction changing, and some integrated educational games with judo techniques (Ukemi and newaza basic resistances). Opportunities should be created for all children in education process. It might be appropriate to organize 60-minute training programs per day for preschool children. In judo training, integrating musical educational games for 4-6 years old can be used as a different education method to support movement skill development. A wide range of balls (various types and sizes), hoops, climbing stairs, rope and other similar equipment to play, climbing, running, jumping and throwing objects safely are used to have fun in education of children; Ukemi, Tachiwaza, Newaza might be used. Judo's basic training, ukemi (falling techniques) can be trained with different drills. In addition, Judo's basic principles of balance disruption of four main and four intermediate directions of educational games might be applied in planning of educational games. In this age range (4-6 years old), planning on development of learned skills apply programs that support body coordination and balance development (Balyi, Way, Higgs, 2016). Judo's basic principles to control power and minimum power with principle of maximum work can be given by games (Kano, 2005). Intermediate physical skill development studies, main them of educational games can be given to children as pleasure. In this period, judo educational games should be created opportunities for children to learn, so inspirational training areas should be created. It is envisaged that the basic Judo (Ukemi, Tachiwaza and Newaza basic principles) training programs, which improve quickness, speed and coordination skills, might be structured and training area and materials are ergonomic for all 
children. It would be appropriate to create a checklist for each child to monitor progress of studies and children. The mentioned table is prepared for evaluation of each exercise. The following table is an example. Coaches can also use their own templates that are similar to this table.

Table 3. Individual Judo development follow-up profile course teacher for 4-6-year-old children (Individual assessment grades)

\begin{tabular}{|c|c|c|c|c|}
\hline \multirow[t]{2}{*}{$J U D O$} & \multicolumn{2}{|l|}{ Name Surname: } & \multirow{2}{*}{$\begin{array}{l}\text { Age: } \\
\text { Evaluation }\end{array}$} & \multirow[b]{2}{*}{ Generalization } \\
\hline & Start & Improvement & & \\
\hline \multicolumn{5}{|l|}{ Body Control } \\
\hline Balance on one leg & $\begin{array}{l}\text { Transition from a single foot } \\
\text { balance position to a circular } \\
\text { position }\end{array}$ & $\begin{array}{c}\text { Straight forward } \\
\text { movement }\end{array}$ & $\begin{array}{l}\text { Development } \\
\text { of movement } \\
\text { form }\end{array}$ & $\begin{array}{c}\text { 1t was } \\
\text { developed }\end{array}$ \\
\hline Walking on Line & $\begin{array}{l}\text { Walk on line right and left side } \\
\text { ukemi }\end{array}$ & $\mathrm{x}$ & $\mathrm{x}$ & $\mathrm{x}$ \\
\hline Creep & Newaza Creep & $\mathrm{x}$ & $\mathrm{x}$ & $\mathrm{x}$ \\
\hline Forward & forward mae ukemi & & & \\
\hline \multicolumn{5}{|l|}{ locomotor } \\
\hline Forward Jumping & Leaping backwards ukemi & - & - & $\begin{array}{c}\text { Working on } \\
\text { again }\end{array}$ \\
\hline Double foot forward & $\begin{array}{l}\text { Double foot forward backwards } \\
\text { ukemi }\end{array}$ & $\mathrm{x}$ & & \\
\hline \multicolumn{5}{|l|}{ Object control } \\
\hline Catch & Special kumikat of the dirl & $\mathrm{x}$ & $\mathrm{x}$ & $\mathrm{x}$ \\
\hline Kicking & $\begin{array}{c}\text { Ashiwaza sweeping foundation } \\
\text { drills }\end{array}$ & $\mathrm{x}$ & $\mathrm{x}$ & $\mathrm{x}$ \\
\hline Two-handed grip & Tachiwaza basic drills & $\mathrm{x}$ & $\mathrm{x}$ & $\mathrm{x}$ \\
\hline Ellen's diripl & Newaza drills & - & - & $\begin{array}{l}\text { Working on } \\
\text { again }\end{array}$ \\
\hline Diripl's Feet & Newaza drills & - & - & $\begin{array}{l}\text { Working on } \\
\text { again }\end{array}$ \\
\hline
\end{tabular}

\section{Discussion and Conclusion}

With long-term development of athletes, elite athletes and high performance in recent years, it has created an intensive application area in many countries, in our country, Ministry of Youth and Sports General Directorate of Sports Education, Sports Talent Selection and Sport Directorate in Olympics. In addition to the Olympic Games NOC (National Olympic Committee of Turkey) Sportsman Supply Project, Turkish Children's Physical Fitness Norms' work was done (GSGMSEDB, Costa et al, 2000; Mengütay et al, 2002)

In Turkey as well as the whole world, the ability to choose and make a process, following each country's unique cultural and social level by ensuring success of this program is not expected to be productive. In order to be successful, it is necessary to think about all factors and to make appropriate planning and program, and to be presented to individuals in a compatible way.

Due to this practice and guidance, athletes can serve as a gear of this wheel and benefit in their own countries. It is important for success of program to ensure that successful athletes make career planning by experts and continue their contributions to sport world. In the four-year strategy plans of federations, these stages are discussed in detail and they are reviewed the literature studies (Özyürek at al, 2015). In this context, Turkey can be applied in different countries based on the above-mentioned application, "excellence and lifelong participation in judo" preparing long-term development model judoka might be a long-term roadmap. In this road map, it is very important to include training of qualified instructors in implementation of preschool education programs. In this respect, judo teachers have a good playground, a good playmate, a good game manager, a good environmental organizer, improved communication and empathy skills, seminars for the training and updating of individuals who have skills and knowledge to realize these activities. It is considered that it should have action plans covering education programs.

We must accept unconditionally the effective use of all these information and materials with game (Koçyiğit, Tuğluk, Kök, 2007).

One of the most important factors, which educators to integrate basic training methods of judo in a game, is that child has knowledge and skills to use in this development process. For this reason, in long-term development model, training and continuous development of qualified trainers for 4-6 years old judo trainings, which includes active start phase, is emphasized again. Training programs for judo trainers of this nature need to be planned and organized. TJF (JDO 
Turkey Federation) should include this issue in training program.

LTAD, unlike DMSP, is based on long-term athletic development model of different physiological, physical and psychological determinants, act on the basis of a biological development processes continuum (Balyi and Hamilton, 1995; Balyi and Hamilton, 2004; Balyi et al., 2013). It is observed that the claims put forward in LTAD models have an impact on the approach and growth principles of children and training and principles of growth (Cote at all, 1999; Cote et all, 2007; Balyi and Hamilton, 2004).

In light of information and impressions obtained the idea of LTAD models implementation for children and adolescents is not based on controlled research and findings but long term planning is considered as a more widespread opinion that implementation might be more beneficial than harm (Bompa, 1995; Suslov, 2002; Ford et al., 2011; Açıkada, 2016).

As a result, basic judo education of 4-6 years old girls and boys improve brain function, coordination, motor, social and leadership skills, emotional intelligence, imagination and self-confidence; strengthen bones and muscles, increase flexibility, improve posture and balance, reduce stress and provide sleep pattern, maintain healthy weight, enable children to act in a skilled manner and help them to enjoy being active. The first stage of a female in age group of 4-6 years was started with opinions of LTAD experts based on mentioned methods to recognize sport, learn and contribute to start active stage of being a distinguished athlete. It is thought that this study contributes to a field as a reference that can be used by all technical staff, manager and clubs working in every field.

\section{Acknowledgements APPENDIX}

LTAD: Long-Term Athletes Development

EJU: European Judo Association

OEP: Olympic Education Program

NOC: National Olympic Committee of Turkey

IOC: International Olympic Committee

NOC: National Olympic Committee of Turkey

GSGMSEDB: T.C. General Directorate of Youth and Sports Directorate of Sports Education

DMSP: Sport Participation Development Model,

JEP: Judo training program (Ukemi, Tachiwaza and Newaza Foundation Dirils)

Ukemi: Falling

Judo: Far East Defense Sport

Ju: Softness, flexibility

Do: The way (philosophically).

Kake: Throw

Tachiwaza: Standing technical groups in judo sport

Newaza: Technical groups on judo sport

Uchikomi: Judo special technique to apply the serial application method.

\section{References}

Açıkada, C. (2016). Long term sportsman development programs: Which Scientific Foundations are Living, Journal of Sport Sciences, Hacettepe Journal of Sport Sciences, 27 (2), 84-100.

Balyi, I., \& Hamilton, A. (1995). The Concept of Long-Term Athlete Development. Strength and Conditioning Coach, $3(2), 5-6$.

Balyi, I., \& Hamilton, A. (2004). Long-Term Athlete Development: Trainability İn Childhood and Adolescence. Olympic Coach, 16(1), 4-9. 8.

Balyi, I. (1998). Long-Term Planning Of Athlete Development, Multiple Periodisation, Modeling and Normative Data.” Fhs: The Uk's Quarterly Coaching Journal, (1), 8-11.

Balyi, I. (2001). Sport System Building and Long-Term Athlete Development in Canada: The Situation and Solutions. Coaches Report: The Official Publication of the Canadian Professional Coaches Association, 8(1), 25-28.

Balyi, I., \& Hamilton, A. (2004). Long-term athlete development update. FHS-LEEDS-, 6-8.

Balyi, I., Way, R., \& Higgs, C. (2013). Long-term Athlete Development. Human Kinetics. 
Balyi, I., Way, R., \& Higgs, C. (2016). Long Term Sports Development, Sports Publishing House, Ankara.

Bompa, T. (1995). From Childhood To Champion Athlete. West Sedona, Az: Veritas Publishing

Bompa, T. O. (2007). Training Theory and Method Development, Sports Publishing, Ankara.

Brosse, M., \& Matsumoto, D. (1999). Judo A Sport and A Way of Life, Interatıonal Judo Federatıon.

Canadian Sport for Life. (2005). Long-Term Athlete Development Resource Paper. Canadian Sport Centres.

Coşan, F., \& Demir, A. (2000). Turkish Standards Compliance Children's Physical/Sedentary 8-14 age Group, Istanbul Practice (practice model in guiding children to sports in Turkey), Istanbul Olympic Games organizing committee of preparation and training publications, Istanbul.

Cote, J., Bake, J., \& Abernethy, B. (2007). Practice and Play in the Development of Sport Expertise. In R. Eklund, G.Tenenbaum (Eds.), Handbook of Sport Psychology, 184-202; 3. Ed.). Hoboken, NJ: Wiley.

Cote, J., Bekr, B., \& Abernethy, B. (1999). A Development framework for the acquisition of Expertisein Team Sports, 89-114.

Demiral, Ş. (2007). Talent Selection in the Women's Judo (Master Thesis), Marmara University Institute of Health Sciences, Istanbul.

Demiral, Ş. (2010). Investigation of Effects of Judo Educational Games on Development of Motor Skills in 7-12 years old Children (Doctorate Thesis). Marmara University Health Sciences Institute, Istanbul.

Department of Education (2013). Fundamental Movement Skills Book 1_Learning, Teaching and Assessment.

file:///users/senguljudo/desktop/2018__developing_physical_literacy.pdf).

Ford, Pr., Croix M., Lloyd R., Meyers R., Moosavi Jo, Till K., \& Williams C. (2011). The Long-Term Athlete Development Model: Physiological Evidence and Application. Journal of Sports Sciences, 29(4), 389-402.

Kano, Y., \& Murata, N. (2005). Jigoro KANO Mind over Muscle (writings from the founder of judo), JAPAN: Kodansha USA.

Koçyiğit, S., Tuğluk, N. M., \& Kök, M. (2007). Game as an Educational Activity in the Child's Development Process, Issue: 16.

Mengütay, S., Demir, A., \& Coşan, F. (2002). Supply for Olympics Athletes Sports Basic Education Project (Children's Fitness to Practice Model for Directed in Turkey), Istanbul Olympic Games Preparation and Regulatory Board of Education Publications No: 2, Istanbul.

Özbey, S., \& Güzel, P. (2009). Examination of Long-Term Olympic Education Programs, Hacettepe Journal of Sport Sciences, 20 (4), 117-131.

Özkan, A., \& Özkan, A. (2016). The Supreme Funds Participation (Long Term Model Development, Ireland, the United Kingdom, for example, to Turkey Adaptation, International Journal of Science Culture and Sport, 2016; 4:(S1 1): 93-99

Özyürek, A., Özkan, İ., Begde, Z., \& Yavuz, N. F. (2015). Physical Education and Sports in Preschool, Special Issue 3, International Journal of Science Culture and Sport.

Suslov, F. (2002). About The Sensitive age Periods in the Development of Physical Capacities. Modern Athlete and Coach, 40, 31-33.

T.C. General Directorate of Youth and Sports. (2005). Ability in Sport for Olympics and Orientation to Sport Project, Ankara.

\section{Copyrights}

Copyright for this article is retained by the author(s), with first publication rights granted to the journal.

This is an open-access article distributed under the terms and conditions of the Creative Commons Attribution license which permits unrestricted use, distribution, and reproduction in any medium, provided the original work is properly cited. 